\title{
Comparative analysis of the effects of antidepressant therapy on emotional improvement in patients with Parkinson's disease complicated with depression
}

Jing Chen

The Affiliated Hospital of Guizhou Medical University

\section{Pengfei $X \mathbf{u}$}

The People's Hospital of Pujiang County

Xunyi Guo

The Affiliated Hospital of Guizhou Medical University

Tao Zou (D417083430@qq.com)

The Affiliated Hospital of Guizhou Medical University

Research article

Keywords: Depression, HAMD, Parkinson's disease, therapy

Posted Date: March 10th, 2020

DOl: https://doi.org/10.21203/rs.3.rs-16540/v1

License: (c) (i) This work is licensed under a Creative Commons Attribution 4.0 International License.

Read Full License 


\section{Abstract}

Objective This study aimed to compare the effects of different antidepressant therapies on emotional improvement in patients with Parkinson's disease (PD) complicated with depression, and to explore effective strategies in PD treatment.

Methods A total of 328 patients with idiopathic PD admitted to the Affiliated Hospital of Guizhou Medical University and Second People's Hospital of Guiyang were consecutively selected. The 17-item Hamilton Depression Scale (HAMD-17) was used to screen whether patients with PD exhibited depressive symptoms. The treatment group included 131 eligible patients, but 118 completed the study. The patients were randomized to conventional treatment, conventional treatment + escitalopram, conventional treatment + pramipexole, and conventional treatment + transcranial magnetic stimulation (TMS) groups. The effects of antidepressant therapies were assessed using the HAMD score reduction rate after 2 and 4 weeks of treatment.

Results The prevalence of PD complicated with depression was $53.4 \%$, and was significantly higher in females than in males. The response rate in the conventional treatment, escitalopram, pramipexole, and TMS groups was $34.48 \%, 93.10 \%, 87.09 \%$, and $75.86 \%$, respectively. This indicated that the escitalopram group had the best efficacy. After 2 and 4 weeks of treatment, the HAMD scores of each group were significantly lower than those before treatment. The reduction in HAMD scores was the most significant in the pramipexole group after 2 weeks of treatment and in the escitalopram group after 4 weeks of treatment.

Conclusion Escitalopram, pramipexole, and high-frequency TMS had better efficacy in patients with PD complicated with depression, with escitalopram being the most effective.

\section{Introduction}

Globally, Parkinson's disease (PD) is considered to be the second most prevalent neurodegenerative disease secondary to Alzheimer's disease. Its prevalence increases with age and it is one of the most common age-related brain diseases[1], affecting approximately $1-2 \%$ of the elderly population aged more than 65 years [2].. Furthermore, the number of patients with PD is estimated to increase by $50 \%$ by 2030 [3], and hence has received increasing global awareness. Clinically, PD is mainly characterized by dyskinesia, and its typical symptoms include static tremor, stiffness, bradykinesia, and postural instability. Although PD is generally considered to be a typical dyskinesia, basically all patients with PD are complicated with nonmotor symptoms, thus increasing the overall burden of PD [4]. Advances in the studies of PD have increasingly focused on the nonmotor symptoms of PD, which mainly include depression, anxiety, sleep disorders, and cognitive dysfunction [5]; depression in PD (dPD) is the most common nonmotor symptom in patients with $\operatorname{PD}[6,7]$ Numerous studies have demonstrated that compared with motor symptoms, nonmotor symptoms, especially depression and cognitive dysfunction, have greater effects on the quality of life of patients with PD [8]. If early diagnosis and reasonable 
treatments of nonmotor symptoms in patients with PD can be realized, the quality of life of the patients can be greatly improved and the burdens of their families and society as a whole can be reduced.

At present, the prevalence of $\mathrm{dPD}$ is generally $40-50 \%$ [9-11], but in fact less than $20 \%$ of the patients receive antidepressant therapy [12]. If $\mathrm{dPD}$ is not treated in time, the quality of life of patients is severely affected and the risk of suicide increases [13]. The risk factors for the incidence of dPD include education level, sex, age, and other general factors, as well as the severity, duration of PD, family history, and other specific factors $[7,14]$.

Currently, no antidepressants, specifically for dPD, are available, and most of them are general antidepressants, such as selective serotonin reuptake inhibitors (SSRIs), 5-HT selective norepinephrine reuptake inhibitors (SNRIs), tricyclic antidepressants (TCAs), and monoamine oxidase inhibitor antidepressants [15]. Several new antidepressant regimens have emerged in clinical practice in recent years, including cognitive therapy, electroconvulsive therapy, transcranial magnetic stimulation (TMS), and other psychological and physical therapies [16], but no therapy has a definite efficacy [11].

In conclusion, the pathogenesis of dPD remains unclear. At present, a few studies have reported on dPD treatment, and the efficacy of several therapies for $\mathrm{dPD}$ is unknown. At the same time, in addition to the side effects of drugs, some antidepressants may aggravate the motor symptoms of PD. In this setting, this study aimed to explore effective strategies for treating dPD by comparing the effects of different antidepressant therapies on emotional improvement for these patients, thereby providing beneficial theoretical references for the clinical selection of medications and therapies.

\section{Methods}

\subsection{Participants}

From October 2017 to December 2018, 328 patients with idiopathic PD admitted to the Neurology Department and Ward of the Affiliated Hospital of Guizhou Medical University and Second People's Hospital of Guiyang were consecutively selected. An on-site questionnaire survey was conducted for the patients. All patients voluntarily participated in the study and provided written informed consent. The inclusion criteria were as follows: (1) typical symptoms and signs of PD; (2) meeting the diagnostic criteria of United Kingdom Parkinson's Disease Society Brain Bank; (3) stages 2-4 of Hoehn-Yahr ( $\mathrm{H}-\mathrm{Y})$ scale; and (4) patients with no communication disorders, who were able to complete the questionnaire independently. The exclusion criteria were as follows: (1) PD caused by diseases such as essential tremor, cerebrovascular diseases, central nervous system infection and poisoning, and craniocerebral trauma; (2) patients with Parkinson-plus syndromes, such as multiple-system atrophy, progressive supranuclear palsy, corticobasal degeneration, and dementia with Lewy bodies; (3) patients with severe cognitive dysfunction or mental disorders; (4) patients receiving antidepressant therapy in the last 3 months.

\subsection{Study tools}




\subsubsection{Questionnaire of general data}

The questionnaire of general data was self-made. It included the name, sex, age, educational level, disease course, occupation, ethnicity, marital status, work, and other data of patients with PD.

\subsection{2 $\mathrm{H}-\mathrm{Y}$ staging scale}

The $\mathrm{H}-\mathrm{Y}$ scale, published by Melvin Yahr and Margaret Hoehn in 1967, is the most widely used PD staging scale worldwide [17]. This scale is based on the severity of overall dyskinesia of PD involving the progression of unilateral to bilateral dyskinesia and progressive damage in gait and balance [18].

\subsubsection{Hamilton Depression Scale}

The Hamilton Depression Scale (HAMD) was developed by Hamilton in 1960.It is considered to be the gold standard for measuring the severity of depressive symptoms [19] and has been widely used in clinical trials for the antidepressant therapy of patients with depression [20] This scale included the 17item version, 21-item version, and 24-item version. This study used the HAMD-17.

\subsection{Study methods}

\subsubsection{Questionnaire}

On-site assessment was performed regarding general data, HAMD-17, and Hoehn-Yahr staging for patients with PD. The relevant rating in this study was conducted by trained persons to avoid human errors.

\subsubsection{Grouping and therapies}

Patients with a HAMD score of $>17$ were enrolled in the study. The study process was explained to them before starting the procedure. The patients voluntarily participated in the study, and written informed consent was obtained. A total of 131 patients were included in the study, and 118 finally completed it.

Patients meeting the inclusion criteria were randomly assigned to group $\mathrm{A}(n=29)$, group $\mathrm{B}(n=29)$, group $\mathrm{C}(n=31)$, and group $\mathrm{D}(n=29)$. Patients in group A were treated with conventional anti-PD drugs (levodopa and benserazide tablets, trade name: Madopar; Shanghai Roche Pharmaceutical Co., Ltd.; dose: $0.25-1 \mathrm{~g} /$ day; no intervention was made according to the patient's routine dose). Patients in group $B$ were treated with conventional anti-PD drugs + escitalopram oxalate (trade name: Lexapro; Xi'an Janssen Pharmaceutical Ltd.; initial dose: $5 \mathrm{mg}$; if the patients had no other symptoms, the dose was increased to $10 \mathrm{mg} /$ day after 1 week). Patients in group C were treated with conventional anti-PD drugs + pramipexole (trade name: Sifrol; Shanghai Boehringer Ingelheim Pharmaceutical Co., Ltd.; initial dose: $0.375 \mathrm{mg} /$ day in week 1 ; if the patients had no other symptoms, the dose was increased to $0.75 \mathrm{mg} /$ day in week 2 and $1.5 \mathrm{mg} /$ day in week 3). Patients in group $D$ were treated with conventional anti-PD drugs + high-frequency rTMS (magnetic stimulator and coils were purchased from Wuhan Yiruide Medical Company, YRD CCY-I type magnetic stimulator). During the treatment, the patients were in a quiet 
environment and sat in an armchair or laid on the treatment bed, keeping the whole body relaxed. The coil was tangent to the surface of the skull. The coil was moved to search the optimum location that caused the abductor pollicis brevis to generate the maximum motor-evoked potential amplitude. Then, the center of the intersection of the two circles of the coil was fixed at this point. The handle was vertically directed to the occipital side, ensuring that the coil position was fixed during the stimulation. The left dorsal lateral prefrontal cortex (DLPFC) was stimulated with a high frequency of $5 \mathrm{~Hz}$. The magnetic field strength was $100 \%$ resting threshold. Each sequence had 5 pulses, and the sequence interval was $1 \mathrm{~s}$, with 600 sequences/time and a total of 3000 pulses. The treatment was performed five times per week. Clinical comparison was performed after 4 weeks of treatment for the four groups.

\subsubsection{Response evaluation}

The HAMD assessment was performed before treatment and after 2 and 4 weeks of treatment. The therapeutic effects of the four groups were evaluated according to the HAMD reduction rate. The clinical response evaluation criteria were as follows: HAMD reduction rate $\geq 75 \%$ indicated complete recovery; $\geq 50 \%$ indicated marked effectiveness; $\geq 25 \%$ indicated effectiveness; and $<25 \%$ indicated ineffectiveness. The clinical overall response rate $=$ (number of complete recovery cases + number of markedly effective cases + number of effective cases)/total number of cases in this group $\times 100 \%$.

\subsubsection{Statistical tools and methods}

The Epidata 3.1 software was used for double entry and error detection, and the SPSS 19.0 software was used for data analysis and statistics. The therapeutic effects among the treatment groups were compared using one-way analysis of variance. The significant level $a$ was 0.05 .

\section{Results}

2.1 General data of the respondents

A total of 328 patients with PD were investigated, including 173 male (52.7\%) and 155 female patients $(47.3 \%)$. The age range was $41-84$ years, with a mean of $(66.04 \pm 9.73)$ years. The duration of the disease was $0.3-12$ years, with an average of $(3.52 \pm 2.61)$ years. The average number of years of education received by the patients was $(7.13 \pm 3.17)$ years. Of the participants, 207 were workers $(63.1 \%)$ and 121 were unemployed persons (36.9\%); 279 were married (85.1\%) and 49 were widowed/divorced (14.9\%); and 275 were Han Chinese (83.8\%) and 53 were non-Han Chinese (16.2\%). The details are listed in Table 1. 
Table 1

Comparison of the demographic data of HAMD scores in PD patients $(x \pm s, \min )$

\begin{tabular}{|c|c|c|}
\hline Group & & HAMD-17 score \\
\hline \multirow[t]{3}{*}{ Sex } & Male $(n=173)$ & $18.63 \pm 6.75$ \\
\hline & Female $(n=155)$ & $24.41 \pm 8.94$ \\
\hline & $\mathrm{t}$ & $5.178^{*}$ \\
\hline \multirow[t]{3}{*}{ Occupation } & Yes $(n=207)$ & $20.71 \pm 8.85$ \\
\hline & No $(n=121)$ & $23.49 \pm 7.85$ \\
\hline & $\mathrm{t}$ & $3.203^{\star \star}$ \\
\hline \multirow[t]{3}{*}{ Ethnicity } & Han Chinese $(n=275)$ & $22.05 \pm 8.96$ \\
\hline & Non-Han Chinese $(n=53)$ & $23.53 \pm 7.43$ \\
\hline & $\mathrm{t}$ & 1.063 \\
\hline \multirow[t]{3}{*}{ Marital status } & Married $(n=279)$ & $21.09 \pm 6.36$ \\
\hline & Widowed/divorced $(n=49)$ & $24.53 \pm 7.43$ \\
\hline & $\mathrm{t}$ & $3.163^{* \star}$ \\
\hline \multicolumn{3}{|l|}{${ }^{*} \mathrm{P}<0.05$} \\
\hline \multicolumn{3}{|l|}{${ }^{\star *} P<0.01$} \\
\hline Parkinson's dis & Ise (PD); The Hamilton Depre & Ion Scale (HAMD) \\
\hline
\end{tabular}

\subsection{Prevalence Of DPD}

Of the 328 patients with PD surveyed, 153 had no depressive symptoms (HAMD score $<7$ points), accounting for $46.6 \% ; 175$ had depression (HAMD score $\geq 7$ points), with a prevalence of $53.4 \%$. Of the 175 patients with depression, 44 (13.4\%) had mild (HAMD score: 7-17 points), 102 (31.2\%) had moderate (HAMD score: 18-24 points), and 29 (8.8\%) had severe (HAMD score > 24 points) depression. Details are available in Table 2. 
Table 2

Prevalence of patients with dPD

\begin{tabular}{|llllll|}
\hline Grouping & Nondepression & \multicolumn{2}{l}{ Depression } & & \\
\cline { 3 - 6 } & & Mild & Moderate & Severe & Total \\
\hline HAMD score & $<7$ points & $7-17$ points & $18-24$ points & $>24$ points & $\geq 7$ points \\
\hline Number $(n)$ & 153 & 44 & 102 & 29 & 175 \\
\hline Percentage $(\%)$ & 46.6 & 13.4 & 31.2 & 8.8 & 53.4 \\
\hline depression in PD (dPD); The Hamilton Depression Scale (HAMD) & & \\
\hline
\end{tabular}

2.3 Comparison Among The Various Treatment Groups

The one-way analysis of variance revealed no significant differences in sex, age, duration of disease, education level, and HY staging among the groups $(F=0.090,0.158,0.226,0.421$, and 1.105 ; all $P>0.05)$. The results of the analysis showed that the study grouping was reasonable. Details are shown in Table 3.

Table 3

Comparison among the various treatment groups $(x \pm s, \min )$

\begin{tabular}{|c|c|c|c|c|c|c|}
\hline \multirow[t]{2}{*}{ Grouping } & \multicolumn{2}{|l|}{ Sex } & \multirow{2}{*}{$\begin{array}{l}\text { Age } \\
\text { (year) }\end{array}$} & \multirow{2}{*}{$\begin{array}{l}\text { Disease } \\
\text { course } \\
\text { (year) }\end{array}$} & \multirow{2}{*}{$\begin{array}{l}\text { Educational } \\
\text { level } \\
\text { (year) }\end{array}$} & \multirow{2}{*}{$\begin{array}{l}\mathrm{H}-\mathrm{Y} \\
\text { staging }\end{array}$} \\
\hline & Male & Female & & & & \\
\hline $\begin{array}{l}\text { Group } A(n= \\
29)\end{array}$ & 11 & 18 & $63.7 \pm 8.88$ & $3.79 \pm 3.07$ & $7.13 \pm 3.51$ & $2.78 \pm 0.69$ \\
\hline $\begin{array}{l}\text { Group } B(n= \\
29)\end{array}$ & 12 & 17 & $\begin{array}{l}64.34 \pm \\
9.68\end{array}$ & $3.59 \pm 3.70$ & $6.72 \pm 2.87$ & $2.82 \pm 0.57$ \\
\hline $\begin{array}{l}\text { Group } C(\mathrm{n}= \\
31)\end{array}$ & 12 & 19 & $\begin{array}{l}64.35 \pm \\
8.93\end{array}$ & $3.71 \pm 2.47$ & $6.25 \pm 3.27$ & $2.73 \pm 0.66$ \\
\hline $\begin{array}{l}\text { Group } D(\mathrm{n}= \\
29)\end{array}$ & 12 & 17 & $\begin{array}{l}64.17 \pm \\
8.37\end{array}$ & $4.14 \pm 2.47$ & $7.02 \pm 3.10$ & $2.64 \pm 0.68$ \\
\hline F value & 0.090 & & 0.158 & 0.226 & 0.421 & 1.105 \\
\hline$P$ value & 0.965 & & 0.925 & 0.878 & 0.732 & 0.350 \\
\hline
\end{tabular}

2.4 Comparison of the efficacy among the four groups after treatment

After 4 weeks of treatment, the response rate was $34.48 \%$ in the conventional treatment group, $93.10 \%$ in the escitalopram group, $87.09 \%$ in the pramipexole group, and $75.86 \%$ in the TMS group. The pairwise comparison in the response rate among the four groups showed that the differences were statistically significant $(P<0.05)$, suggesting that the efficacy in the conventional group was inferior to that in the 
other three groups. Moreover, the escitalopram group had the best efficacy, followed by the pramipexole group. Details are shown in Table 4.

Table 4

Comparison of the efficacy among the four groups after treatment $\mathrm{n}(\%)$

\begin{tabular}{|llllll|}
\hline Grouping & $\begin{array}{l}\text { Complete } \\
\text { recovery }(\mathrm{N})\end{array}$ & $\begin{array}{l}\text { Markedly } \\
\text { effective }(\mathrm{N})\end{array}$ & $\begin{array}{l}\text { Effective } \\
(\mathrm{N})\end{array}$ & $\begin{array}{l}\text { Ineffective } \\
(\mathrm{N})\end{array}$ & $\begin{array}{l}\text { Overall response } \\
\text { rate (\%) }\end{array}$ \\
\hline $\begin{array}{l}\text { Group A }(\mathrm{n} \\
=29)\end{array}$ & 0 & 1 & 9 & 19 & 34.48 \\
$\begin{array}{l}\text { Group B (n } \\
=29)\end{array}$ & 11 & 11 & 5 & 2 & $93.10^{\mathrm{a}, \mathrm{b}, \mathrm{c}}$ \\
$\begin{array}{l}\text { Group C (n } \\
=31)\end{array}$ & 7 & 13 & 7 & 4 & $87.09^{\mathrm{a}, \mathrm{c}, \mathrm{d}}$ \\
$\begin{array}{l}\text { Group D (n } \\
=29)\end{array}$ & 5 & 7 & 10 & 7 & $75.86^{\mathrm{a}, \mathrm{b}, \mathrm{d}}$ \\
\hline
\end{tabular}

2.5 Comparison of changes in HAMD scores before and after treatment for the four groups

The HAMD scores of each group before and after treatment were compared using independent-samples $t$ test. The therapeutic effects among the groups were compared by analysis of variance. The pairwise comparisons were conducted using the least significant difference method. The results showed that the HAMD scores of each group after 2 and 4 weeks of treatment were lower than those before treatment, and the differences were statistically significant $(P<0.05)$. After 2 weeks of treatment, the reduction in HAMD scores was the most significant in the pramipexole group, with statistical differences compared with the other groups $(P<0.05)$. No significant difference was found between the escitalopram and TMS groups $(P>0.05)$. After 4 weeks of treatment, the escitalopram group was the most significant in terms of reduction in HAMD score, with statistically significant differences compared with the other groups $(\mathrm{P}<$ 0.05). No significant differences were found between the pramipexole group and the TMS group ( $P>$ 0.05). Details are available in Table 5. 
Table 5

Comparison of HAMD scores before and after treatment in each group $(x \pm s$, points)

\begin{tabular}{|c|c|c|c|c|c|c|}
\hline Time & $\begin{array}{l}\text { Group A (n } \\
=29)\end{array}$ & $\begin{array}{l}\text { Group B ( } n= \\
29)\end{array}$ & $\begin{array}{l}\text { Group C ( } \mathrm{n}= \\
31)\end{array}$ & $\begin{array}{l}\text { Group D ( } \\
=29)\end{array}$ & $\begin{array}{l}\mathrm{F} \\
\text { value }\end{array}$ & $\begin{array}{l}P \\
\text { value }\end{array}$ \\
\hline Before treatment & $\begin{array}{l}23.38 \pm \\
4.72\end{array}$ & $23.93 \pm 4.40$ & $23.90 \pm 3.97$ & $22.48 \pm 4.19$ & 0.719 & 0.543 \\
\hline $\begin{array}{l}\text { After } 2 \text { weeks of } \\
\text { treatment }\end{array}$ & $\begin{array}{l}21.34 \pm \\
4.53^{*}\end{array}$ & $\begin{array}{l}18.83 \pm \\
4.44^{\star \star, a, b}\end{array}$ & $\begin{array}{l}16.87 \pm \\
2.83^{\star \star, a, b, c}\end{array}$ & $\begin{array}{l}19.10 \pm \\
4.31^{\star \star, a, d}\end{array}$ & 3.854 & 0.011 \\
\hline $\begin{array}{l}\text { After } 4 \text { weeks of } \\
\text { treatment }\end{array}$ & $\begin{array}{l}19.14 \pm \\
4.80^{\star *}\end{array}$ & $\begin{array}{l}12.52 \pm \\
4.69^{* *}, \mathrm{a}, \mathrm{b}, \mathrm{d}\end{array}$ & $\begin{array}{l}14.77 \pm \\
2.12^{\star \star}, \mathrm{a}, \mathrm{c}\end{array}$ & $\begin{array}{l}15.93 \pm \\
4.50^{* \star}, \mathrm{a}, \mathrm{c}\end{array}$ & 9.795 & 0.001 \\
\hline
\end{tabular}

\section{Discussion}

Studies have suggested that depression has a higher incidence in patients with PD [21]. Although depression is a common symptom of other diseases and usually occurs in the elderly, available evidence suggests that depression is more common in patients with PD than in the normal elderly population and those with other chronic and disabling diseases (such as osteoarthritis) [22]. Depression can occur in all stages of PD, even before tremors, bradykinesia, and other motor symptoms, suggesting that depression may be a precursor of PD [23].

In the present study, 328 patients with PD were studied in the two hospitals in Guiyang. The results showed that the prevalence of dPD was $53.4 \%$, including mild (13.4\%), moderate (31.2\%), and severe (8.8\%) depression. The prevalence was $65 \%$ in female patients and $44 \%$ in male patients. Foreign studies showed that the prevalence of dPD was $40-50 \%$ [9-11], consistent with the findings of this study. However, the incidence of $\mathrm{dPD}$ is different in different studies. Foreign studies revealed a relatively high prevalence of moderate-to-severe depression; the average prevalence of dysthymia, mild depression, and severe depression was $22.5 \%, 36.6 \%$, and $24.8 \%$, respectively[24]. Compared with foreign data, the proportion of moderate-to-severe depression in dPD in China was low. An epidemiological study by Yu et al. [25] showed that the incidence of dPD in China was $69.23 \%$, of which mild-to-moderate depression accounted for $65.38 \%$ and severe depression accounted for only $3.85 \%$. This might be because of the difference in the diagnostic criteria for depression, scales in the survey, and study populations [26]. Overall, the prevalence of $\mathrm{dPD}$ is relatively high.

At present, the most commonly used and effective drug for the treatment of PD is levodopa. However, most patients after treatment with levodopa for a period of time develop complications such as reduced efficacy, psychiatric symptoms, dyskinesia, "on-off" phenomenon, wearing-off, and so on. Moreover, levodopa is ineffective in patients with dPD. It is often administered in combination with antidepressants, leading to serious adverse reactions. DA receptor agonists can improve the sensitivity of patients to DA replacement therapy, and usually achieve better therapeutic effects in combination with levodopa. Pramipexole is a novel DA receptor agonist with high selectivity for D2 and D3 receptors, and its affinity for D3 receptors is significantly higher than that for D2 receptors [27]. It not only has a good therapeutic 
effect on PD-related motor symptoms but also can improve the depressive symptoms of patients and their quality of life [28]. Therefore, it may be a potential antidepressant drug [29], which is more beneficial for patients with dPD. A multicenter, parallel-controlled, and open-label study compared the effects of pramipexole and sertraline in treating PD with major depressive disorder. The results showed that both drugs could improve symptoms of $\mathrm{dPD}$, but pramipexole was more effective [27].

At present, SSRIs are the most commonly used drugs for treating patients with dPD. Given their fewer adverse drug reactions and good tolerance, they are commonly used in clinical settings, especially suitable for the elderly. As shown in the survey, $62.9 \%$ of patients with dPD were administered SSRIs, $20 \%$ chose novel non-SSRI antidepressants (such as venlafaxine and mirtazapine), and only $7.4 \%$ chose TCA [30]. Although fewer case reports showed that SSRIs might aggravate motor symptoms of PD, it was not confirmed in several large-scale studies[31]. A recent double-blind, randomized, placebo-controlled trial[32] explored the efficacy of paroxetine versus venlafaxine sustained-release capsules in the treatment of dPD; 115 patients with dPD were treated for 12 weeks. The results showed that both paroxetine and venlafaxine could significantly improve the symptoms of dPD and did not aggravate the motor symptoms of PD. However, previous studies on SSRIs for the treatment of dPD focused on paroxetine, and related studies suggested insufficient evidence for the efficacy of fluoxetine, sertraline, and citalopram in treating dPD [33]. Especially for the newly marketed SSRI escitalopram, few studies reported its usage in treating $\mathrm{dPD}$, which were underpowered to support its efficacy in these patients.

TMS is a novel painless, noninvasive physical therapy and technique widely used in the studies and treatments of depression. According to the frequency, it includes high-frequency rTMS (frequency $>1 \mathrm{~Hz}$ ) and low-frequency rTMS (frequency $\leq 1 \mathrm{~Hz}$ ). Different frequencies have different effects on brain nerve cells: high frequency leads to excitation, and low frequency produces inhibition. The left DLPFC is involved in the generation and regulation of positive emotions, and the right DLPFC participates in the generation and regulation of negative emotions. Studies have found that the left DLPFC function is abnormally decreased, while the right one is significantly increased in patients with depression. Both high-frequency rTMS stimulation of the left DLPFC and low-frequency rTMS stimulation of the right DLPFC are effective in treating depression [34].

This study compared the therapeutic effects of the conventional anti-PD therapy with escitalopram, pramipexole, and high-frequency rTMS on dPD, and found that depression in all treatment groups showed different degrees of improvement compared with that before treatment. After the conventional anti-PD therapy, the HAMD scores of the patients decreased slightly, suggesting emotional improvement in patients compared with that before treatment. It might be because of the anti-PD therapy. The physical symptoms of the patients were relieved, which alleviated their painful experience caused by the disease and increased their confidence in the treatment, thus contributing to improved emotional disorders.

The results of this study showed that compared with other therapies, pramipexole could quickly and effectively improve depression, and was also favorable for improvements in cognitive and motor symptoms. After 2 weeks of treatment, the pramipexole group had more HAMD score reductions 
compared with the other groups, indicating that pramipexole had a better antidepressant effect in the first 2 weeks of treatment. The reason for the shorter onset time of pramipexole might be that its targets were not limited to the nigrostriatal region, and it also had agonistic effects on DA D2 and D3 receptors in the hippocampus and amygdala, which could not only improve anxiety, depression, and other nonmotor symptoms of patients but also significantly improve the motor symptoms and quality of life of patients with PD. Furthermore, it could quickly improve motor symptoms, such as bradykinesia and limb tremor, in the early stage of drug administration [35]. The improvement in motor symptoms in the early stage of treatment could improve the quality of life and depression of patients.

This study found that escitalopram was better than pramipexole in terms of therapeutic effect after 4 weeks of treatment. By analyzing the reduction rate of HAMD, the response rate of escitalopram after 4 weeks was $93 \%$, which was higher than $87 \%$ in the pramipexole group, $75 \%$ in the rTMS group, and $34 \%$ in the conventional treatment group, indicating that the antidepressant effect of long-term administration of escitalopram was more significant. Escitalopram was a highly selective 5-HT reuptake inhibitor that competitively inhibited the reuptake process by binding to the $5-\mathrm{HT}$ reuptake pathway, thereby increasing the 5-HT concentration in the synaptic gap. It continuously stimulated the postsynaptic membrane, and finally the antidepressant effect could be achieved, which was 100 times the effect of citalopram on dextrorotatory enantiomer [36]. Therefore, it had powerful antidepressant effects.

Although single administration of pramipexole and escitalopram was effective in improving the depressive symptoms of dPD, early combination of escitalopram and pramipexole did not show a significant advantage over monotherapy [37]. Moreover, the novel antidepressant therapy TMS was more commonly used in the combination of antidepressant therapies. Studies [38] showed that rTMS combined with SSRIs could effectively improve the depressive symptoms of dPD.

This study showed that high-frequency rTMS effectively improved depressive symptoms, cognitive function, and dyskinesia in patients with dPD. However, the antidepressant effect of high-frequency rTMS was not as good as that of escitalopram and pramipexole. Previous studies showed that both high- and low-frequency rTMS had antidepressant effects, but high-frequency rTMS was more effective [39]. A study found that high-frequency TMS stimulation of the frontal lobe significantly improved the activities of daily living, motor function score, turning, and buttoning ability of patients [40], suggesting that highfrequency rTMS could also improve dyskinesia in patients with PD and facilitate recovery of motor function.. Fregni et al. [41] found that rTMS, such as fluoxetine, could increase cerebral blood perfusion in patients with PD, regulate cortical excitability, improve cerebral blood circulation, affect catecholamine metabolism in the brain, promote the release of endogenous DA, increase DA around ipsilateral caudate nucleus, inhibit the decomposition of DA in the cerebral nervous system, and regulate the excitability of the direct and indirect circuits of globus pallidus of the affected striatum.

In conclusion, escitalopram, pramipexole, and high-frequency rTMS had good effects on dPD. Escitalopram had the best antidepressant effect, while pramipexole had a faster onset time. Although 
high-frequency rTM was inferior to the aforementioned two drugs in terms of therapeutic effects, it might be a good auxiliary treatment as a painless and noninvasive therapeutic regimen.

\section{Abbreviations}

Parkinson's disease (PD); depression in PD (dPD); The 17-item Hamilton Depression Scale (HAMD-17) ; transcranial magnetic stimulation (TMS); selective serotonin reuptake inhibitors (SSRIs); selective norepinephrine reuptake inhibitors (SNRIs);; tricyclic antidepressants (TCAs); The Hamilton Depression Scale (HAMD); dorsal lateral prefrontal cortex (DLPFC).

\section{Declarations}

Ethics approval and consent to participate : This study was reviewed and approved by the ethics committee of the affiliated hospital of Guizhou Medical University, and all subjects voluntarily signed the informed consent.

Consent for publication: Written informed consent to publish this information was obtained from study participants.

Availability of data and materials: The datasets used and/or analysed during the current study are available from the corresponding author on reasonable request.

Competing interests: The authors declare that they have no competing interests.

Funding: Not applicable

\section{Authors' contributions :}

Jing Chen: designed experiments, wrote papers and obtained research funds

Pengfei Xu: implementation of research, data collection, data analysis

Xunyi Guo: statistical analysis

Tao Zou: research guidance, technical support, paper revision

\section{Acknowledgements:}

Thanks to jiao ling, department of neurology, affiliated hospital of guizhou medical university for her strong support for the implementation of this study, and na chongkun, department of psychology, affiliated hospital of guizhou medical university for her guidance on the operation of TMS. The research was supported by the science and technology cooperation program of guizhou department of science and technology -- affiliated hospital of guizhou medical university. 


\section{References}

1. Kataoka H, Sawa N, Sugie K, Ueno S: Can dopamine agonists trigger tactile hallucinations in patients with Parkinson's disease? J Neurol Sci 2014, 347(1-2):361-363.

2. Capriotti T, Terzakis K: Parkinson Disease. Home Healthc Now 2016, 34(6):300-307.

3. Calabrese VP: Projected number of people with Parkinson disease in the most populous nations, 2005 through 2030. Neurology 2007, 69(2):223-224; author reply 224.

4. Lim SY, Lang AE: The nonmotor symptoms of Parkinson's disease-an overview. Mov Disord 2010, 25 Suppl 1:S123-130.

5. Han JW, Ahn YD, Kim WS, Shin CM, Jeong SJ, Song YS et al: Psychiatric Manifestation in Patients with Parkinson's Disease. J Korean Med Sci 2018, 33(47):e300.

6. Aarsland D, Bronnick K, Ehrt U, De Deyn PP, Tekin S, Emre M et al: Neuropsychiatric symptoms in patients with Parkinson's disease and dementia: frequency, profile and associated care giver stress. $J$ Neurol Neurosurg Psychiatry 2007, 78(1):36-42.

7. Zhang TM, Yu SY, Guo P, Du Y, Hu Y, Piao YS et al: Nonmotor symptoms in patients with Parkinson disease: A cross-sectional observational study. Medicine (Baltimore) 2016, 95(50):e5400.

8. Menon B, Nayar R, Kumar S, Cherkil S, Venkatachalam A, Surendran K et al: Parkinson's Disease, Depression, and Quality-of-Life. Indian J Psychol Med 2015, 37(2):144-148.

9. Go CL, Rosales RL, Joya-Tanglao M, Fernandez HH: Untreated depressive symptoms among cognitively-intact, community dwelling Filipino patients with Parkinson disease. Int J Neurosci 2011, 121(3):137-141.

10. van der Hoek TC, Bus BA, Matui P, van der Marck MA, Esselink RA, Tendolkar I: Prevalence of depression in Parkinson's disease: effects of disease stage, motor subtype and gender. J Neurol Sci 2011, 310(1-2):220-224.

11. Menza M, Dobkin RD, Marin H, Mark MH, Gara M, Buyske S et al: A controlled trial of antidepressants in patients with Parkinson disease and depression. Neurology 2009, 72(10):886-892.

12. Mayeux R, Stern Y, Williams JB, Cote L, Frantz A, Dyrenfurth I: Clinical and biochemical features of depression in Parkinson's disease. Am J Psychiatry 1986, 143(6):756-759.

13. Edwards E, Kitt C, Oliver E, Finkelstein J, Wagster M, McDonald WM: Depression and Parkinson's disease: a new look at an old problem. Depress Anxiety 2002, 16(1):39-48.

14. Cui SS, Du JJ, Fu R, Lin YQ, Huang P, He YC et al: Prevalence and risk factors for depression and anxiety in Chinese patients with Parkinson disease. BMC Geriatr 2017, 17(1):270.

15. Zhuo C, Xue R, Luo L, Ji F, Tian H, Qu H et al: Efficacy of antidepressive medication for depression in Parkinson disease: a network meta-analysis. Medicine (Baltimore) 2017, 96(22):e6698.

16. Troeung L, Egan SJ, Gasson N: A meta-analysis of randomised placebo-controlled treatment trials for depression and anxiety in Parkinson's disease. PLoS One 2013, 8(11):e79510. 
17. Kotagal V, Bohnen NI, Muller ML, Frey KA, Albin RL: Cerebral Amyloid Burden and Hoehn and Yahr Stage 3 Scoring in Parkinson Disease. J Parkinsons Dis 2017, 7(1):143-147.

18. Giladi N, Nicholas AP, Asgharnejad M, Dohin E, Woltering F, Bauer L et al: Efficacy of Rotigotine at Different Stages of Parkinson's Disease Symptom Severity and Disability: A Post Hoc Analysis According to Baseline Hoehn and Yahr Stage. J Parkinsons Dis 2016, 6(4):741-749.

19. M H: A rating scale for depression. J Neurol Neurosurg Psychiatry 1960, 23:56-62

20. Bobo WV, Anglero GC, Jenkins G, Hall-Flavin DK, Weinshilboum R, Biernacka JM: Validation of the 17item Hamilton Depression Rating Scale definition of response for adults with major depressive disorder using equipercentile linking to Clinical Global Impression scale ratings: analysis of Pharmacogenomic Research Network Antidepressant Medication Pharmacogenomic Study (PGRNAMPS) data. Hum Psychopharmacol 2016, 31(3):185-192.

21. Timmer MHM, van Beek M, Bloem BR, Esselink RAJ: What a neurologist should know about depression in Parkinson's disease. Pract Neurol 2017, 17(5):359-368.

22. Nilsson FM, Kessing LV, Sorensen TM, Andersen PK, Bolwig TG: Major depressive disorder in Parkinson's disease: a register-based study. Acta Psychiatr Scand 2002, 106(3):202-211.

23. Marsh L: Depression and Parkinson's disease: current knowledge. Curr Neurol Neurosci Rep 2013, 13(12):409.

24. Slaughter JR, Slaughter KA, Nichols D, Holmes SE, Martens MP: Prevalence, clinical manifestations, etiology, and treatment of depression in Parkinson's disease. J Neuropsychiatry Clin Neurosci 2001, 13(2):187-196.

25. Wu Y PX, Yang SR, Ouyang YJ, Li MY, Yu JM, Chen HB, Li Z: The incidence and the related factors of the depression in Parkinson's disease. J Pract Med 2015(16).

26. Reijnders JS, Ehrt U, Weber WE, Aarsland D, Leentjens AF: A systematic review of prevalence studies of depression in Parkinson's disease. Mov Disord 2008, 23(2):183-189; quiz 313.

27. Barone P, Scarzella L, Marconi R, Antonini A, Morgante L, Bracco F et al: Pramipexole versus sertraline in the treatment of depression in Parkinson's disease: a national multicenter parallel-group randomized study. J Neurol 2006, 253(5):601-607.

28. Zis AP GF: The amine hypothesis. In:Paykel ES, ed.Handbook of Affective Disorders. London:Churchill Livingstone 1982, 13(4):175-190.

29. Rektorova I, Rektor I, Bares M, Dostal V, Ehler E, Fanfrdlova Z et al: Pramipexole and pergolide in the treatment of depression in Parkinson's disease: a national multicentre prospective randomized study. Eur J Neurol 2003, 10(4):399-406.

30. Muslimovic D, Post B, Speelman JD, Schmand B: Cognitive profile of patients with newly diagnosed Parkinson disease. Neurology 2005, 65(8):1239-1245.

31. Gony M, Lapeyre-Mestre M, Montastruc JL, French Network of Regional Pharmacovigilance C: Risk of serious extrapyramidal symptoms in patients with Parkinson's disease receiving antidepressant drugs: a pharmacoepidemiologic study comparing serotonin reuptake inhibitors and other antidepressant drugs. Clin Neuropharmacol 2003, 26(3):142-145. 
32. Baldwin DS: Escitalopram: efficacy and tolerability in the treatment of depression. Hosp Med 2002, 63(11):668-671.

33. Neuropsychology and Behavioral Neurology Group and Parkinson's Disease and Dyskinesia Group, Neurology Branch, Chinese Medical Association. Guidelines for diagnostic criteria and management of Parkinson's disease complicated with depression, anxiety, and psychotic disorder. Chin J Neurol 2013, 46(1): 56-60.

34. Wang LN PF, Li YF: Effects of low frequency repetitive transcranial magnetic stimulation on treatment-resistant depression and cognitive function. Chin J Rehabil Med 2013, 28(6):544-548.

35. Lemke MR: Dopamine agonists in the treatment of non-motor symptoms of Parkinson's disease: depression. Eur J Neurol 2008, 15 Suppl 2:9-14.

36. Wang JC OY, Li WY, et al. : The second phase clinical trial of escitalopram for the treatment of the major depressive disorder J Phych 2008, 21(5):330-333.

37. Wang GQ HL, Zhao ZX.: Clinical observation of pramipexole in the treatment of Parkinson's disease complicated with depression. Stroke Nervo Dis 2013, 20(04):231-233.

38. Boggio PS, Fregni F, Bermpohl F, Mansur CG, Rosa M, Rumi DO et al: Effect of repetitive TMS and fluoxetine on cognitive function in patients with Parkinson's disease and concurrent depression. Mov Disord 2005, 20(9):1178-1184.

39. Heumann R, Moratalla R, Herrero MT, Chakrabarty K, Drucker-Colin R, Garcia-Montes JR et al: Dyskinesia in Parkinson's disease: mechanisms and current non-pharmacological interventions. $J$ Neurochem 2014, 130(4):472-489.

40. Kedzior KK, Reitz SK, Azorina V, Loo C: Durability of the antidepressant effect of the high-frequency repetitive transcranial magnetic stimulation (rTMS) In the absence of maintenance treatment in major depression: a systematic review and meta-analysis of 16 double-blind, randomized, shamcontrolled trials. Depress Anxiety 2015, 32(3):193-203.

41. Fregni F, Pascual-Leone A: Technology insight: noninvasive brain stimulation in neurologyperspectives on the therapeutic potential of rTMS and tDCS. Nat Clin Pract Neurol 2007, 3(7):383393. 